\title{
CpG-28 Oligodeoxynucleotide
}

National Cancer Institute

\section{Source}

National Cancer Institute. CpG-28 Oligodeoxynucleotide. NCI Thesaurus. Code C62280.

A synthetic oligodeoxynucleotide, containing unmethylated $\mathrm{CpG}$ motifs derived from bacterial DNA, with immunostimulatory activities. A CpG oligodeoxynucleotide (CpG ODN) binds to and activates a Toll-like receptor 9 (TLR9) and is taken up into cells by endocytosis; once internalized, it may activate numerous signaling transduction pathways resulting in the release of multiple cytokines. Through activation of TLR9, a CpG ODN can directly stimulate B-lymphocytes, dendritic and NK cells, resulting in an increase in innate immunity and antibody-dependant cell cytotoxicity (ADCC). Additionally, a CpG ODN can indirectly modulate T-cell responses, through the release of cytokines (IL-12 and IFN gamma), to induce a preferential shift to the Th1 (helper) phenotype resulting in enhanced CD8+ cellular cytotoxicity. 